OPEN ACCESS

Edited by:

Attila Mócsai,

Semmelweis University, Hungary

Reviewed by:

Shuji Mizumoto,

Meijo University, Japan

Peter Daniel Burrows,

University of Alabama

at Birmingham, United States

${ }^{*}$ Correspondence:

Julia Y. Wang

julia@curandis.com

Michael H. Roehr

roehrlm@mskccc.org

${ }^{\dagger}$ These authors have contributed equally to this work and share

senior authorship

Specialty section:

This article was submitted to

Autoimmune and

Autoinflammatory Disorders,

a section of the journal

Frontiers in Immunology

Received: 13 March 2021

Accepted: 05 May 2021

Published: 25 May 2021

Citation:

Lee J, Rho J-h, Roehrl MH and Wang JY (2021) Dermatan Sulfate Is a Potential Regulator

of IgH via Interactions With

Pre-BCR, GTF21, and BiP ER Complex in Pre-B Lymphoblasts.

Front. Immunol. 12:680212. doi: 10.3389/fimmu.2021.680212

\section{Dermatan Sulfate Is a Potential Regulator of IgH via Interactions With Pre-BCR, GTF2l, and BiP ER Complex in Pre-B Lymphoblasts}

\author{
Jongmin Lee ${ }^{1}$, Jung-hyun Rho ${ }^{2}$, Michael H. Roehrl ${ }^{\text {*t }}$ and Julia Y. Wang ${ }^{4 * t}$ \\ ${ }^{1}$ Department of Molecular and Cell Biology, Boston University School of Dental Medicine, Boston, MA, United States, \\ ${ }^{2}$ MP Biomedicals New Zealand Limited, Auckland, New Zealand, ${ }^{3}$ Department of Pathology and Human Oncology and \\ Pathogenesis Program, Memorial Sloan Kettering Cancer Center, New York, NY, United States, ${ }^{4}$ Curandis, New York, \\ NY, United States
}

Dermatan sulfate (DS) and autoantigen (autoAg) complexes are capable of stimulating autoreactive CD5+ B1 cells. We examined the activity of DS on CD5+ pre-B lymphoblast NFS-25 cells. CD19, CD5, CD72, PI3K, and Fas possess varying degrees of DS affinity. The three pre-BCR components, Ig heavy chain mu $(\mathrm{lgH})$, VpreB, and lambda 5, display differential DS affinities, with lgH having the strongest affinity. DS attaches to NFS-25 cells, gradually accumulates in the ER, and eventually localizes to the nucleus. DS and IgH colocalize on the cell surface and in the ER. DS associates strongly with 17 ER proteins (e.g., BiP/Grp78, Grp94, Hsp90ab1, Ganab, Vcp, Canx, Kpnb1, Prkcsh, Pdia3), which points to an IgH-associated multiprotein complex in the ER. In addition, DS interacts with nuclear proteins ( $\mathrm{Ncl}$, Xrcc6, Prmt5, Eftud2, Supt16h) and Lck. We also discovered that DS binds GTF2I, a required gene transcription factor at the $\mathrm{lg} H$ locus. These findings support DS as a potential regulator of $\mathrm{IgH}$ in pre-B cells at protein and gene levels. We propose a (DS•autoAg)-autoBCR dual signal model in which an autoBCR is engaged by both autoAg and DS, and, once internalized, DS recruits a cascade of molecules that may help avert apoptosis and steer autoreactive B cell fate. Through its affinity with autoAgs and its control of $\mathrm{IgH}$, DS emerges as a potential key player in the development of autoreactive B cells and autoimmunity.

Keywords: autoimmunity, precursor BCR, dermatan sulfate (DS), Ig heavy chain, GTF2I, BiP

\section{INTRODUCTION}

Autoimmunity, an immune response against the body self, is an intriguing phenomenon. Autoimmunity is caused by autoreactive lymphocytes and/or autoantibodies that target autoantigens (autoAgs) present in single or multiple tissue types throughout the body, leading to over 80 recognized types of autoimmune diseases, ranging from systemic diseases such as lupus and rheumatoid arthritis to organ-specific diseases such as type 1 diabetes. Autoimmune phenomena are also strongly linked to various malignancies such as lymphoma and leukemia. Despite extensive research, understanding how autoreactive lymphocytes survive rounds of immune editing and 
elimination has remained largely elusive. Although it is now accepted that autoreactive cells are positively selected by autoAgs, the underlying mechanism is unclear. Furthermore, several hundred autoAgs have been identified across seemingly unrelated tissue locations or biologic functions. Yet these different autoantigens can all elicit a similar autoimmune response such as clonal expansion of autoreactive cells or production of specific autoantibodies. Better understanding of these processes will greatly advance the field of autoimmunity.

We have proposed that the glycosaminoglycan dermatan sulfate (DS) is a key missing player in autoimmunity in that (i) self-molecules with affinity to DS have a high propensity to be autoAgs and (ii) DS•autoAg complexes work in concert to stimulate autoreactive B cells $(1,2)$. In our initial study, we had injected mice with various glycosaminoglycans, including DS, heparan sulfate, chondroitin sulfates A and C, hyaluronic acid, and heparin, and found that DS is the most potent in inducing arthritis in mice (3). When tested in vitro with mouse splenocytes, DS is found to be the most potent in stimulating CD5+ B (B1) cell proliferation and, moreover, DS exerts unique affinity to autoantigens from apoptotic cells, which prompted our hypothesis that DS and autoAgs form complexes and co-operate to stimulate B1 cells (1). We then tested clinical autoantibody standard sera and sera from patients with autoimmune diseases such as lupus and Sjögren syndrome and demonstrated that DS affinity enabled the identification of many more autoAgs than current clinical tests are able to (2). Based on our DS•autoAg affinity hypothesis, we have thus far identified over 200 potential protein autoAgs from cells lines and murine liver and kidney tissues $(2,4-6)$ and autoAgs related to autoimmunity in COVID19 (7-9).

When autoAg•DS complexes encounter B cells expressing autoreactive B cell receptors (autoBCRs), we hypothesize that, while autoAgs engage autoBCRs, DS must engage other signals to ensure successful B1 cell activation leading to further proliferation and differentiation. Neither autoAgs nor DS alone can recruit a sufficient signaling network, as autoAg-autoBCR engagement without co-stimulating factors generally leads to deletion or anergy of the autoreactive cells. In our search for DS receptor(s) in autoreactive B1 cells, we investigated CD5+ pre-B lymphoblast NFS-25 cells, a cell line derived from a spontaneous murine lymphoma (10). The pre-B stage is a crucial checkpoint for positive vs. negative regulation of autoimmunity and for development of mature autoreactive B cells. Precursor BCRs (pre-BCRs) are considered poly- and self-reactive, resembling polyreactive autoBCRs (11). Pre-BCR-mediated signaling has been implicated in positive selection of pre-B cells, proliferation, survival, $\operatorname{IgH}$ allelic exclusion, and $\operatorname{IgH}$ repertoire selection (12). The pre-BCR is composed of a $\mu$ heavy chain $(\mu \mathrm{H}$ or $\operatorname{IgH} \mu$ ) and a germ line-encoded surrogate light chain made of $\lambda 5$ and VpreB (13). Intriguingly, the pre-BCR shapes the IgH repertoire and appears to select particular IgH chains, such as those that express an $\mathrm{H}$-CDR3 with positively charged amino acid residues such as arginines $(14,15)$. Without any bias toward any particular signaling molecule, we carried out a series of experiments and discovered several lines of evidence to support that IgH is a critical DS receptor in a potential dual (DS•autoAg)autoBCR signaling pathway and that DS is a potential regulator of $\mathrm{IgH}$.

\section{MATERIALS AND METHODS}

\section{Cell Culture}

NFS-25 C-3 cells were purchased from the ATCC (CRL-1695) and cultured in complete DMEM supplemented with $10 \%$ fetal bovine serum and a penicillin-streptomycin-glutamine mixture (Invitrogen). For various experiments, cells were cultured in the medium with the addition of DS or heparin $(10,50,100$, or 500 $\mu \mathrm{g} / \mathrm{ml}), 10 \mu \mathrm{g} / \mathrm{ml}$ of LPS, anti-CD5 $(2,5,10 \mu \mathrm{g} / \mathrm{ml})$, anti-IgM (2, $5,10 \mu \mathrm{g} / \mathrm{ml}$ ), or combinations for 3-6 days. Cell proliferation was measured by MTT assays. For apoptosis induction, cells were cultured with $5,10,20,50 \mu \mathrm{M}$ camptothecin (CPT) for various times. Cell apoptosis was monitored by Annexin V-fluorescein isothiocyanate (FITC) and propodium iodide (PI) staining and flow cytometry.

\section{Protein Extraction}

Approximately 200 million NFS-25 cells in $200 \mathrm{~mL}$ cell culture medium were harvested and washed twice with phosphatebuffered saline (PBS). They were suspended in $50 \mathrm{mM}$ phosphate buffer ( $\mathrm{pH}$ 7.4) with Roche Complete Mini protease inhibitor cocktail. Cells were homogenized on ice, followed by sonication on ice for $5 \mathrm{~min}$. The homogenate was centrifuged, and the supernatant was considered the total protein extract and collected. Protein concentrations were measured with the RC DC Protein Assay (Bio-Rad).

\section{DS-Affinity Fractionation}

DS-Sepharose resins were prepared by covalently linking DS (Sigma-Aldrich) to EAH Sepharose $4 \mathrm{~B}$ resins (GE Healthcare) as previously described $(1,2)$. Aliquots of about $5.5 \mathrm{mg}$ of protein extract in $1 \mathrm{ml}$ of $10 \mathrm{mM}$ phosphate buffer (buffer A, pH 7.4) was mixed with $0.35 \mathrm{ml}$ of DS-Sepharose resins and incubated at $4^{\circ} \mathrm{C}$ for 3 hours. After removing the buffer, the resins were washed three times with $1 \mathrm{ml}$ buffer A to remove unbound proteins. Proteins bound to resins were then eluted stepwise and sequentially with $0.2,0.4,0.6,1.0 \mathrm{M} \mathrm{NaCl}$ in buffer A, corresponding to proteins with no, low, medium, to high DS affinity, respectively. For each salt elution, resins were mixed with $1.0 \mathrm{ml}$ of elution buffer for $5 \mathrm{~min}$, then the eluate was collected, and each elution step was repeated three times. Eluted fractions were desalted and concentrated in $5 \mathrm{kDa}$ cut-off Vivaspin centrifugal filters (Sartorius).

\section{Competitive Elution With DS and Heparin}

Proteins were extracted from NFS-25 cells and loaded onto DSSepharose resins as described above. After washing with $10 \mathrm{mM}$ phosphate buffer three times, the resins were divided into two aliquots. In one aliquot, proteins were eluted sequentially with $0.2 \mathrm{ml}$ of $50,100,150,200,400$, and $600 \mu \mathrm{mol} / \mathrm{ml}$ (as disaccharide repeating unit) DS. In the other aliquot, proteins 
were eluted sequentially with $0.2 \mathrm{ml}$ of $50,100,150,200,400$, and $600 \mu \mathrm{mol} / \mathrm{ml}$ (as disaccharide repeating unit) heparin. We assumed approximate molecular weights of $475.4 \mathrm{~g} / \mathrm{mol}$ per disaccharide repeating unit of dermatan sulfate and estimated $593 \mathrm{~g} / \mathrm{mol}$ per disaccharide repeating unit of heparin. Samples of eluted fractions were analyzed by SDS-PAGE, stained with Coomassie blue, and blotted with anti-CD19, anti-CD5, and anti-CD72.

\section{SDS-PAGE and Western Blotting}

SDS-PAGE analysis of proteins was performed with 4-12\% NuPAGE Bis-Tris gels (Invitrogen) with 3-(N-morpholino) propane sulfonic acid running buffer and staining with BioSafe Coomassie G250 (Bio-Rad). Aliquots of $\sim 5 \mu \mathrm{g}$ of proteins were loaded per gel lane. Proteins in gels were transferred onto polyvinylidene fluoride membranes, blocked with tris-buffered saline (pH 7.4) containing $2 \%$ bovine serum albumin, $3 \%$ casein or skim milk, and $0.5 \%$ Tween 20 at $4^{\circ} \mathrm{C}$ overnight. They were incubated with primary antibodies at $25^{\circ} \mathrm{C}$ for $1 \mathrm{~h}$. Primary antibodies tested include anti-CD19 (eBioscience), anti-CD5 (sc6985, Santa Cruz Biotech), anti-CD72 (sc-25265), anti-CD21 (sc7027), anti-CD81 (sc-9158), anti-PI3K (sc-31969), anti-Grp78 (Abcam), anti-Golgin97 (Abcam), biotin anti-CD95 (Fas/APO1 , eBioscience), or biotin rat anti-mouse preBCR (BD Biosciences). Membranes were washed thrice with TBS containing $0.5 \%$ Tween 20 , then incubated with appropriate secondary antibodies conjugated with horseradish peroxidase in blocking buffer at $25^{\circ} \mathrm{C}$ for $1 \mathrm{~h}$, and developed with enhanced chemiluminescence substrate. Secondary antibodies used include goat anti-rabbit IgG-horseradish peroxidase (HRP), anti-goat IgG-HRP, or streptavidin-HRP (BioLegend).

\section{DS-Biotin Isolation of GTF2I}

DS-biotin was synthesized as previously described (1). NFS-25 cells were cultured with and without $20 \mu \mathrm{g} / \mathrm{ml}$ DS-biotin in complete DMEM medium for 3 days. Proteins were extracted from 50 million cells using the MEM-PER extraction kit (Thermo Fisher). Soluble proteins $(1.5 \mathrm{ml})$ and insoluble proteins were separated, and to each tube was added $1.5 \mathrm{ml}$ of $10 \mathrm{mM}$ phosphate buffer and $0.06 \mathrm{ml}$ of NeutrAvidin agarose beads (Pierce). The mixtures were incubated at $4^{\circ} \mathrm{C}$ for $1 \mathrm{~h}$. After washing the beads with PBS four times, bound proteins were released by boiling with SDS-PAGE sample buffer at $100^{\circ} \mathrm{C}$ for $10 \mathrm{~min}$. Proteins from cells cultured with or without DS-biotin were compared side by side by SDS-PAGE analysis. Bands only present in samples from cells cultured with DS-biotin were selected and sequenced by mass spectrometry. In duplicate gels, proteins were transferred onto PVDF membrane, blotted with anti-GTF2I (sc-9943, Santa Cruz Biotech) at 1:1000 dilution, and detected with rabbit anti-goat IgG-HRP at 1:2000 dilution and ECL substrate.

\section{Cellular Protein Biotinylation and DS-Affinity Isolation}

NFS-25 cells cultured in complete DMEM were harvested, washed with ice-cold PBS three times, and resuspended at a concentration of 25,000 cells $/ \mathrm{ml}$ in PBS. To each $1 \mathrm{ml}$ of cells was added $80 \mu \mathrm{l}$ of $10 \mathrm{mM}$ sulfo-NHS-SS-biotin (Pierce) in $\mathrm{H}_{2} \mathrm{O}$ and incubated at room temperature for $30 \mathrm{~min}$. After the reaction, the cells were washed three times with ice-cold PBS and lysed by homogenization. Cell lysates were incubated with $1 \mathrm{ml}$ of DSSepharose resins, and unbound to weakly-bound proteins were washed off extensively with $0.4 \mathrm{M} \mathrm{NaCl}$ in $10 \mathrm{mM}$ phosphate buffer. Tightly bound proteins were eluted with $1.0 \mathrm{M} \mathrm{NaCl}$ in 10 $\mathrm{mM}$ phosphate buffer. The eluate was incubated with $0.2 \mathrm{ml}$ of streptavidin agarose resins (Pierce) at $4^{\circ} \mathrm{C}$ for $1 \mathrm{~h}$. The resins were washed four times with PBS, and bound proteins were eluted by boiling with $0.2 \mathrm{~mL}$ SDS-PAGE buffer for $10 \mathrm{~min}$. The eluted proteins and controls were analyzed by SDS-PAGE, transferred to PVDF membranes, and blotted with streptavidin-HRP to reveal biotinylated proteins. Biotinylated protein gel bands were selected and sequenced by the Taplin mass spectrometry facility at Harvard Medical School (Boston).

\section{Cell Proliferation and $\lg \mu$ Measurement by ELISA}

IgM secreted into the cell culture supernatant was measured by ELISA. Duplicate wells in 96-well plates were coated with rabbit anti-mouse $\mathrm{F}\left(\mathrm{ab}^{\prime}\right)_{2}$ in $0.1 \mathrm{M}$ sodium carbonate buffer ( $\mathrm{pH} 9.4$ ) at $4^{\circ} \mathrm{C}$ overnight. After washing with $0.05 \%$ Tween 20 in PBS three times and blocking with $1 \% \mathrm{BSA}$ at $37^{\circ} \mathrm{C}$ for 1 hour, $100 \mu \mathrm{l}$ of cell culture supernatant was added to each well and incubated at $37^{\circ} \mathrm{C}$ for 1 hour. $\mathrm{IgH} \mu$ heavy chains were detected with goat antimouse $\mu$ conjugated to alkaline phosphatase (SouthernBiotech) and p-nitrophenyl phosphate substrate.

\section{Flow Cytometry}

Cultured cells were collected by centrifugation and washed twice with a staining buffer that contained $1 \%$ bovine serum albumin in PBS (pH 7.2). About 4 million cells were suspended in $0.8 \mathrm{ml}$ of the staining buffer and split into eight $0.1 \mathrm{ml}$ aliquots, $\sim 0.5$ million cells each. Aliquots were stained with 1-3 $\mathrm{gg}$ of antiCD19-FITC, PE anti-CD5-PE, DS-Cy5, or a combination of the three by incubating in the dark at $25^{\circ} \mathrm{C}$ for 1 hour. In another experiment, cells were stained with $1 \mu \mathrm{g}$ of anti-IgM-FITC, antiIgD-FITC, DS-Cy5, or combinations. Stained cells were washed three times with $0.5 \mathrm{ml}$ of the staining buffer, and analyzed with a BD FACS Calibur flow cytometer.

\section{Fluorescence Confocal Microscopy}

DS-conjugated Alexa Fluor 568 (DS-AF568) was prepared in the lab. In brief, $20 \mathrm{mg}$ of DS (Sigma-Aldrich), $1 \mathrm{mg}$ of AF568 hydrazide (Invitrogen), and about $100 \mathrm{mg}$ of N-ethyl-N'-(3dimethylaminopropyl)carbodiimide hydrocholoride were added to $1 \mathrm{ml}$ of $0.1 \mathrm{M}$ MES buffer ( $\mathrm{pH} 5.0$ ). The solution was mixed on a rocker at room temperature $\left(25^{\circ} \mathrm{C}\right)$ for $16 \mathrm{~h}$. The mixture was desalted with a PD-10 desalting column (Sigma-Aldrich) and then purified and concentrated with a $10-\mathrm{kDa}$ cut-off spin column (Pierce). NFS-25 cells were cultured with $10 \mu \mathrm{g} / \mathrm{ml}$ of DS-AF568 for 1-6 days. Cells were fixed with 1\% formalin in PBS at $25^{\circ} \mathrm{C}$ for $15 \mathrm{~min}$ and washed twice with PBS. Cells were stained in $\mathrm{PBS}$ containing $1 \% \mathrm{BSA}$ or $10 \%$ FBS with various antibodies at $4^{\circ} \mathrm{C}$ for $18 \mathrm{~h}$. Antibodies used include: antiCD19-FTIC, anti-CD5-FITC, anti-Grp78-AF488, and anti- $\mu$ - 
FITC (SouthernBiotech). Cell nuclei were stained with $50 \mathrm{nM}$ DAPI at $25^{\circ} \mathrm{C}$ for $15 \mathrm{~min}$. Images were taken with a Zeiss LSM 510 confocal microscope.

\section{RESULTS}

\section{DS Activity on NFS-25 Cell Proliferation and Apoptosis}

In our previous study, when primary mouse spleen cells were cultured with DS, CD5+ B1 cells were found to be specifically stimulated by DS to proliferate (1). To test whether a similar effect holds for CD5+ pre-B cells, we cultured NFS-25 cells with DS, B-cell mitogen lipopolysaccharide (LPS), or medium only. Cell proliferation assays showed no significant difference between NFS- 25 cells cultured with DS, LPS, or medium alone for 3 to 6 days. It is possible that these cells may have to be cultured with a much higher concentration of DS or LPS or for longer time periods to show detectable differences.

In a previous study, we had discovered that DS has strong affinity to apoptotic cells (1). We therefore examined whether this DS-affinity property is also true for NFS-25 cells. In typical NFS- 25 cell cultures, about $5 \%$ to $8 \%$ of cells are observed to be apoptotic and stain positively with DS-Cy5 by flow cytometry. DS-Cy5 staining correlated well with annexin V staining but not with propidium iodide staining, consistent with our previous finding that DS has affinity to apoptotic cells. To further verify DS affinity in cell apoptosis, NFS-25 cell cultures were treated for different periods of time with various amounts of camptothecin (CPT), which triggers apoptosis by binding to the topoisomerase I and DNA complex in cells. As shown by flow cytometry, CPT induced apoptosis in a time- and dose-dependent manner (Supplemental Figure 1). After overnight treatment, $10 \mu \mathrm{M}$ CPT induced apoptosis in $26.8 \%$ of cells, while $50 \mu \mathrm{M}$ CPT induced apoptosis in $41.3 \%$ cells, and all apoptotic cells were positively stained by DS-Cy5. These findings are consistent with our previously reported affinity of apoptotic cells to DS (1). We also tested whether DS could rescue CPT-induced apoptotic cells by co-culturing cells with DS and CPT, but DS did not increase the viability rates of CPT-treated cells.

\section{Possible DS Affinity of CD5, CD72, CD19, PI3K, CD21, or Fas Proteins}

Since we hypothesize that DS•autoAg complexes engage dual signals, with autoAg binding to autoBCR and DS binding to another receptor, we began a search for unknown DS receptors by first screening prominent B1 cell signaling markers. We extracted proteins from NFS-25 cells and fractionated them on DS affinity resins by step-wise elution with $0.2 \mathrm{M}, 0.4 \mathrm{M}, 0.6 \mathrm{M}$, and $1.0 \mathrm{M} \mathrm{NaCl}$, corresponding to unbound or no, low, medium, and high DS affinities, respectively. Unfractionated and fractionated proteins were then separated in SDS-PAGE gels and blotted with antibodies to CD19, CD5, CD72, CD21, CD81, PI3K, Fas/CD95, and others (Figure 1 and Supplemental Figure 2).
CD5 and CD19 are defining markers of B1 cells, and CD72 is a known receptor for CD5. All three proteins were detected in the NFS-25 protein extracts as expected. After DS-affinity fractionation, CD19 was detected in the fractions eluted with 0.4 and $0.6 \mathrm{M} \mathrm{NaCl}$, but not in the unbound ( $0.2 \mathrm{M}$ fraction) or the $1.0 \mathrm{M}$ fraction (Figure 1A). CD5 molecules display a range of DS affinities, with the majority having no affinity but some having low affinity. However, two bands of smaller molecular size were also detected by anti-CD5 in fractions with medium and strong affinity. These findings suggest that CD5 may exist in multiple isoforms, and only some isoforms may associate with DS. CD72 was detected mostly in the $0.4 \mathrm{M}$ fraction, although a higher molecular size version was present in the unbound fraction.

To ensure that the DS-affinity fractionation is indeed due to specific DS interaction but not non-specific binding to the resin, we carried out competitive elution with DS or heparin. NFS-25 protein extracts were loaded onto DS-Sepharose resins and eluted with DS or heparin (Figure 1B). The majority of proteins bound to DS-Sepharose were eluted with DS at concentrations of $0.15,0.2$, or $0.4 \mathrm{M}$, whereas higher concentrations of heparin were needed. Western blotting verified that CD19, CD5, and CD72 were eluted with lower concentration of DS than heparin. These results suggest that proteins identified by our DS-affinity fractionation bind to DS more specifically than to heparin, a structurally similar polyanionic glycosaminoglycan.

We also examined a number of other markers as potential DS receptors (Supplemental Figure 2). Phosphoinositide 3-kinase (PI3K) has been identified in the DS signaling pathway in mouse spleen cell cultures $(16,17)$. We therefore tested its affinity to DS. $\mathrm{PI} 3 \mathrm{~K}$ was detected in both the unbound and $0.4 \mathrm{M}$ fractions. A smaller molecular size version was enriched in the unbound fraction, and a larger version was detected in the $0.4 \mathrm{M}$ and $0.6 \mathrm{M}$ fractions. Fas, also known as apoptosis antigen 1 or CD95, was identified in the unbound, $0.4 \mathrm{M}$, and $0.6 \mathrm{M}$ fractions. Various bands with smaller and larger molecular sizes were also detected in the unbound, 0.4 M, and 0.6 M fractions. CD21 (or CR2) was detected in the unbound fraction.

Our previous study had shown that DS can also stimulate CD5+ cell proliferation in cells from CD19-deficient mice (1). The CD5 protein only partially co-localizes with DS (Supplemental Figure 3). Although the above tested B cell signaling markers were detected in DS-binding factions and the results are consistent with our previous findings from mouse spleen B1 cells (1), these proteins likely associate with DS indirectly via other molecules. Therefore, we continued our search for DS receptors by other means.

\section{DS Trafficking in NFS-25 Cells and Accumulation in the ER}

We tracked the fate of DS trafficking in cells by culturing NFS25 cells with DS-AF568 and examined them by confocal fluorescence microscopy at various time points (Figure 2). After 1 hour, DS appeared faintly on the surface of some cells. After 4 hours, DS association with small bodies, likely 


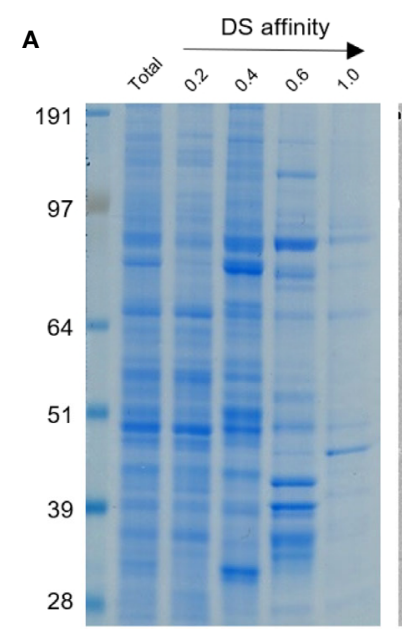

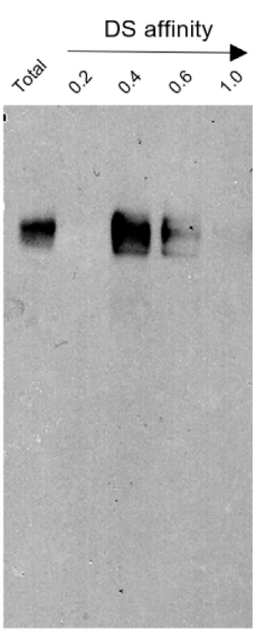

CD19

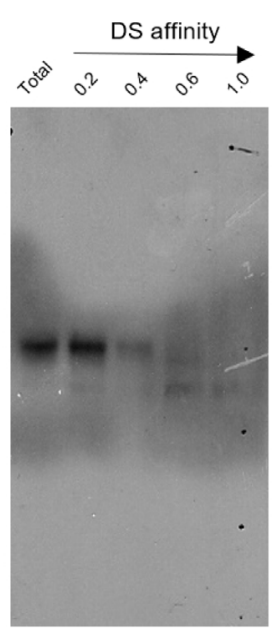

CD5

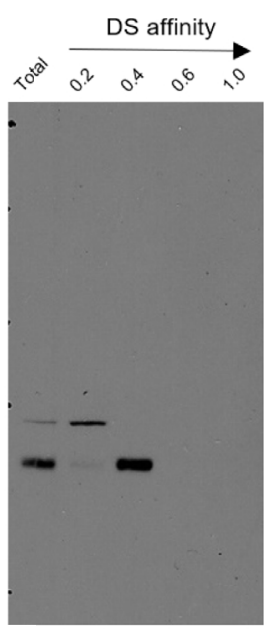

$\mathrm{CD} 72$

B DS Heparin
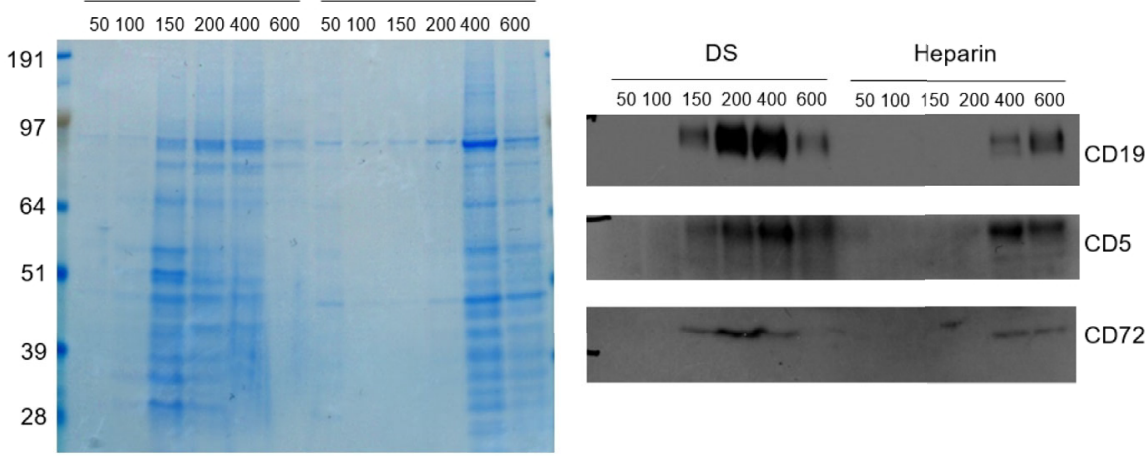

FIGURE 1 | (A) Protein extracts from NFS-25 cells were fractionated with DS-affinity resins and blotted with specific antibodies. Protein lanes correspond to total unfractionated proteins (T) and fractions eluted with $0.2,0.4,0.6$, and $1.0 \mathrm{M} \mathrm{NaCl}$, respectively. (B) NFS-25 proteins loaded onto DS resins were eluted with step gradients of DS or heparin (left: Coomassie blue-stained SDS-PAGE) and blotted with specific antibodies (right), demonstrating competitive binding specificity between DS-resin-binding proteins and DS or heparin. DS and heparin concentrations are expressed as $\mu \mathrm{mol} / \mathrm{ml}$ of disaccharide.

apoptotic cell bodies or dead cell debris, was observed. After 8 hours, some DS molecules were present within viable NFS-25 cells, starting to accumulate in an area adjacent to the nucleus. From 8 hours on, DS accumulation inside cells gradually increased. After 24 hours, DS accumulation in the same intracellular areas intensified and DS was also accumulating in the nucleus. After 48 hours, intracellular DS accumulation appeared to reach a maximum.

As shown in Figure 2, DS did not randomly spread in the cytoplasm upon entering cells but rather accumulated for a significant amount of time in a specific compartment adjacent to the nucleus, consistent with the ER. Moreover, cells with accumulating DS appeared to be activated cells, which are slightly larger than the resting cells. Cells with nuclear dispersion of DS appeared even larger, suggesting nuclear uptake of DS in the synthesis or early mitotic phases of the cell cycle. To define the perinuclear DS-accumulating compartment, we stained the cells with antibodies for ER marker Grp78/BiP and Golgi marker Golgin97. Grp78 was found to co-localize with
DS in the ER (Figure 3A). To further verify Grp78 association with DS, we blotted NFS-25 proteins fractionated by DS affinity with anti-Grp78. Anti-Grp78 detected two strong bands and one faint band between 64 and $97 \mathrm{kDa}$ molecular weight in the unfractionated NFS-25 protein extracts. The top band appeared predominantly in fractions with weak to strong DS affinity, whereas the bottom band appeared in all fractions. This result shows that Grp78 is abundantly expressed and that different forms can be associated with DS with weak to strong affinity (Figure 3B).

\section{Differential DS Affinity of Pre-BRC Components IgH $\mu, \lambda 5$, and VpreB}

The ER-resident protein Grp78 is also known as immunoglobulin heavy chain binding protein $(\mathrm{BiP})$. We investigated whether immunoglobulins were involved in DS interactions in the ER. We stained NFS-25 cells cultured with DS-AF568 with anti-IgM heavy chain $(\operatorname{IgH} \mu$ or $\mu \mathrm{H})$, and, indeed, IgH $\mu$ co-localized with DS in the ER $\operatorname{IgH} \mu$ also co- 


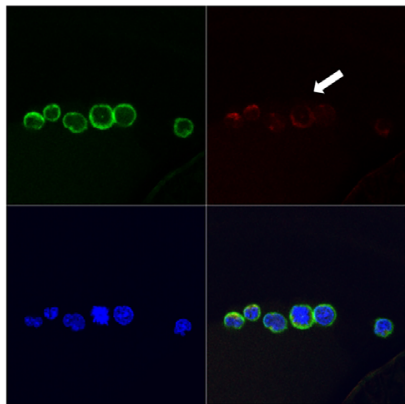

$1 \mathrm{~h}$

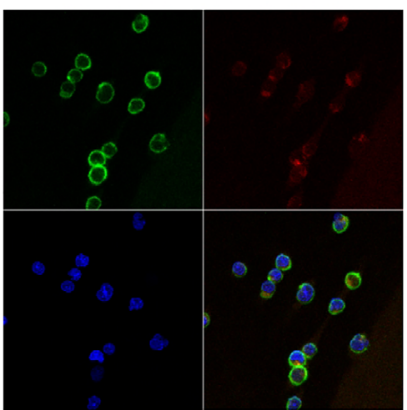

$24 \mathrm{~h}$

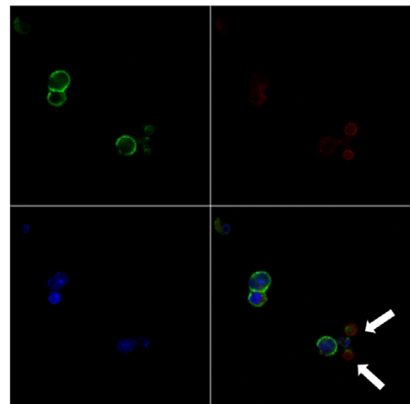

$4 \mathrm{~h}$

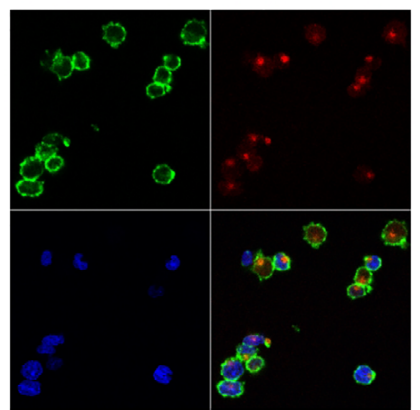

$48 \mathrm{~h}$

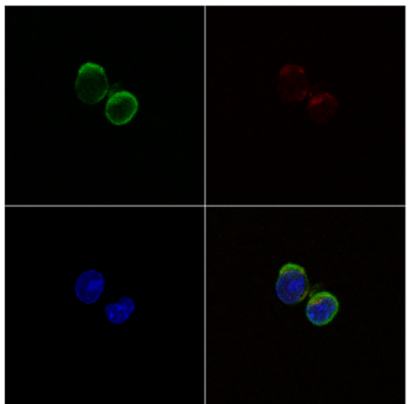

$8 \mathrm{~h}$

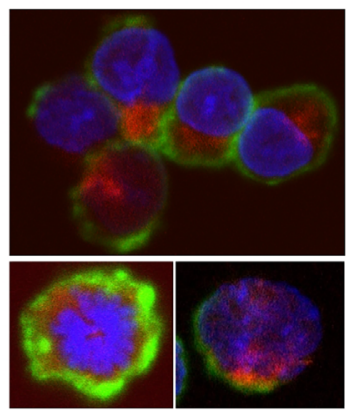

DS in ER and nucleus

FIGURE 2 | NFS-25 cells cultured with DS-AF568 (red) for various times were stained with anti-CD19 (green) and DAPI (blue). After 1 hour, trace amounts of DS were observed on some cell surfaces (white arrow). After 4 hours, DS association with small apoptotic cell bodies was observed (white arrows). From 8 hours on, DS starts to accumulate inside viable cells. At about 48 hours, intracellular DS reaches maximum intensity, with a majority in the ER and some also in the nucleus. Each panel shows four quadrants: green (upper left), red (upper right), blue (lower left), and merged (lower right) channels.

colocalized with DS in distinct clusters on the NFS-25 cell surface (Figure 3D and Supplemental Figure 4).

We then examined whether DS stimulates Ig secretion. NFS25 cells were cultured with either DS, anti-CD19, anti-CD5, antiCD5+DS, anti-CD19+DS, anti-CD5+anti-CD19+DS, or medium only. IgH $\mu$ secretion was measured by ELISA (Supplemental Figure 5). Cells cultured with DS or anti-CD5 did not secrete $\operatorname{IgH} \mu$. Measurable amounts of $\operatorname{IgH} \mu$ were detected in the culture supernatant of cells stimulated with CD19, although the significance of which is not clear. The addition of DS, antiCD5, or anti-CD5+DS to anti-CD19 did not enhance, but rather slightly reduced, IgH secretion when compared to cells cultured with anti-CD19 alone. It is possible that a DS-interacting site and CD5 may be in close proximity to CD19. Consequently, addition of DS or anti-CD5 would partially block and decrease antiCD19-induced stimulation.

Pre-BCRs expressed in pre-B cells are formed by pairs of $\operatorname{IgH}$ $\mu$ chains and surrogate light chains composed of $\lambda 5$ and VpreB proteins. In addition to IgH, we asked whether $\lambda 5$ or VpreB also possess affinity to DS. We fractionated NFS-25 protein extracts and looked for pre-BCR components by blotting with a pre-BCR antibody that recognizes all three components (18). All three components were detected in the total unfractionated NFS-25 protein extract. Surprisingly, DS affinity neatly separated preBCR components into three distinct fractions: $\operatorname{IgH}$ chain appeared in the fraction eluting with $0.6 \mathrm{M} \mathrm{NaCl}, \mathrm{VpreB}$ in the
$0.4 \mathrm{M}$ fraction, and $\lambda 5$ in the $0.2 \mathrm{M}$ fraction (Figure $3 \mathrm{C}$ ). This finding shows that the three components of the pre-BCR display differential affinity to DS.

These two complementary approaches, cell cultures with DS and co-localization microscopy and DS-affinity fractionation with Western blotting, demonstrate a strong interaction between DS and $\operatorname{IgH} \mu$ protein. In summary, DS did not stimulate Ig secretion in NFS-25 cell but rather interacted with $\operatorname{IgH} \mu$ on the cell surface and in the ER.

\section{Discovery of Direct Interaction Between DS and GTF2I}

Given that DS traffics from the cell surface to the ER and nucleus, there could be numerous additional molecules involved in the DS-pre-BCR signaling network. We, therefore, took an unbiased approach to identify DS receptors. NFS-25 cells were cultured with or without DS-biotin for 2 days, proteins were extracted from 50 million cells, and both insoluble and soluble portions were collected. Proteins were then pulled down with NeutrAvidin beads and compared side by side in SDS-PAGE gel lanes. No difference was detected in the insoluble portion, but two distinct bands at $\sim 120 \mathrm{kDa}$ molecular weight were detected in the soluble protein portion of cells cultured with DS-biotin (Figure 4).

Both bands were sequenced by mass spectrometry. The top band identified a single protein with 46 peptide matches to 


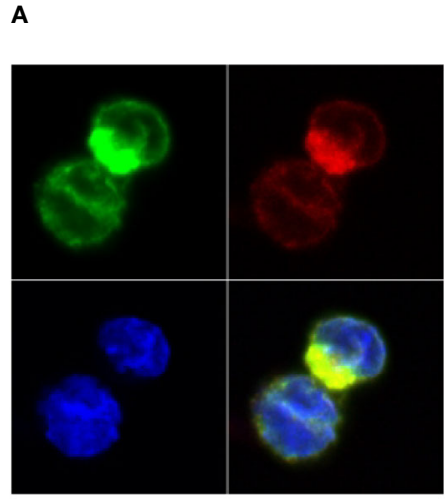

Red - DS; Green - Grp78; Blue - Nuclei

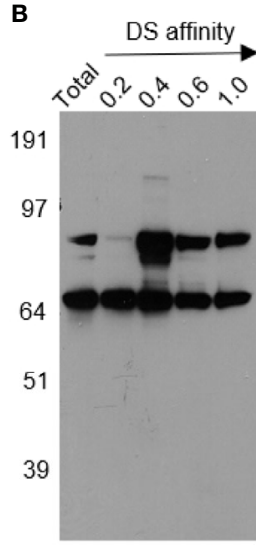

Grp78/BiP
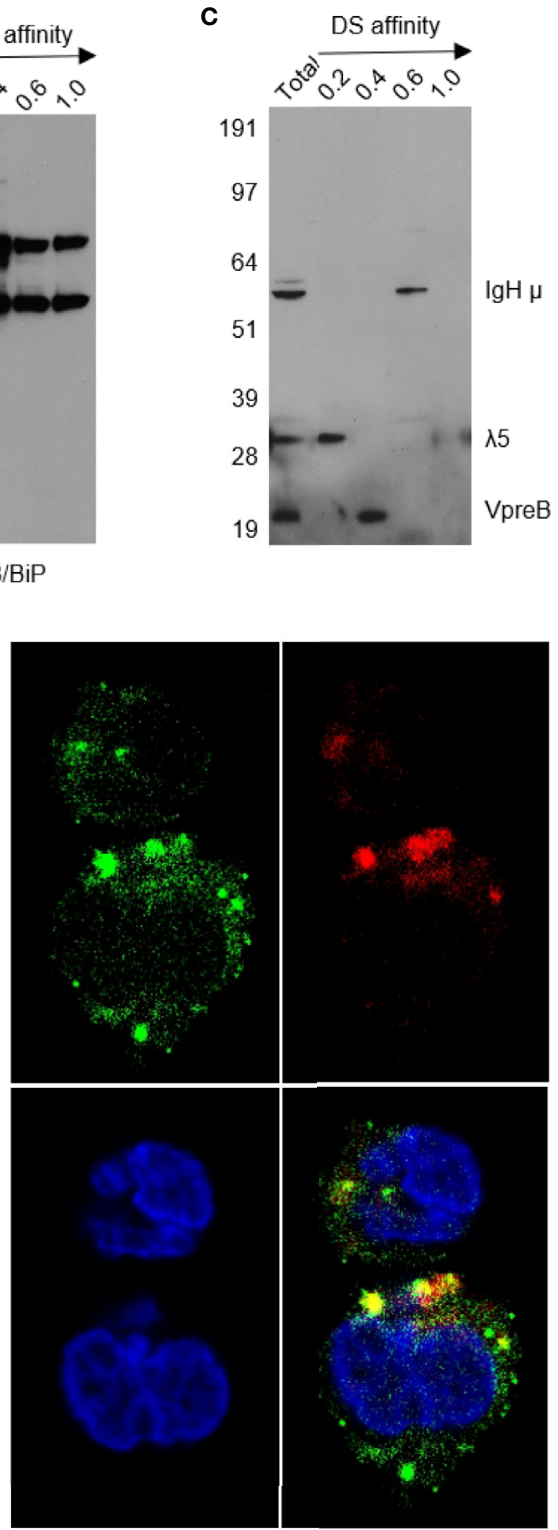

Red - DS; Green - IgH $\mu$; Blue - Nuclei

FIGURE 3 | (A) NFS-25 cells cultured with DS-AF568 and stained with anti-Grp78/BiP confirming the DS-accumulating compartment as the ER. (B) NFS-25 cell proteins fractionated by DS affinity and blotted with anti-Grp78/BiP. (C) NFS-25 cell proteins fractionated by DS affinity and blotted with anti-preBCR, revealing the 3 components of preBCR, each of which has different DS affinity, with IgH $\mu$ having strongest affinity. (D) NFS-25 cells cultured with DS-AF568 and stained with antiIgH $\mu$ showing co-localization on the cell surface and in the ER. Each panel shows four quadrants: green (upper left), red (upper right), blue (lower left), and merged (lower right) channels.

GTF2I, which is impressive as mass spectrometry sequencing of protein bands from cellular extracts usually gives rise to many identifications. The bottom band also overwhelmingly identified GTF2I with 49 peptide matches (Figure 4). A few additional proteins were also identified in the bottom band, including Ubal (12 peptide matches), importin 7 (Ipo7, 4 peptide matches), ATP-citrate synthase (Acly, 3 peptide matches), kinesin heavy chain isoform 5A (Kif5a, 2 peptide matches), Ipo5 (2 peptide matches), and DNA ligase 1 (Lig1, 2 peptide matches). Western blotting also confirmed these protein bands as GTFT2I (general transcription factor II-I), a homolog of human protein TFII-I.

The GTF2I-encoding gene of humans or mouse contains six characteristic repeat motifs and at least 34 exons, and alternative splicing generates many transcript variants (19). Based on 
A

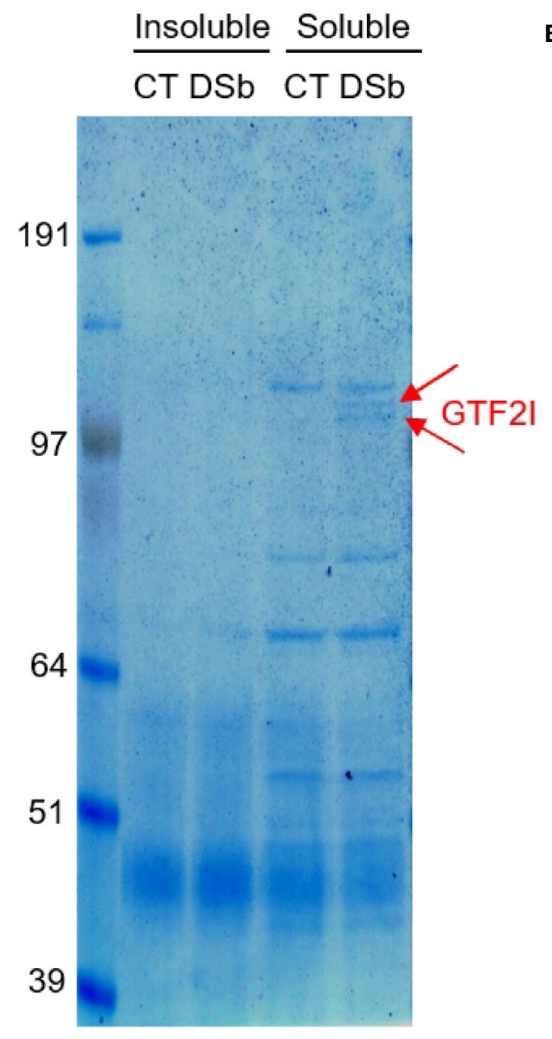

B
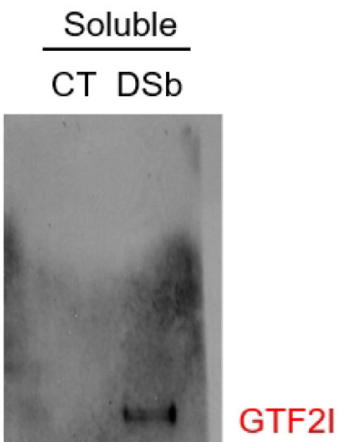

C

MAQVVMSALP AEDEESSESR MVVTFLMSAL ESMCKELAKS KAEVACIAVY ETDVEVVGTE RGRAFVNTRK DFOKDFVKYC VEEEEKAAEM HKMKSTTOAN RMSVDAVEIE TLRKTVEDYF CFCYGKALGK STVVPVPYEK MLRDQSAVVV QGLPEGVAFK HPEHYDLATL KWILENKAGI SFIIKRPFLE PKKHLGGRVL A A A AEAAERSMLS PSGSCGPIKV KTEPTEDSGI SLEMAAAVTVK EESEDPDYYQ YNIQGPSETD GVDEKLPLSK ALQGSHHSSE GNEGTEVEVP AEDSTQHVPS ETSEDPEVEV TIEDDDYSPP TKRLKSTEPP PPPPVPEPAN AGKRKVREFN FEKWNARITD LRKQVEELFE RKYAQAIKAK GPVTIPYPLF QSHVEDLYVE GLPEGIPFRR PSTYGIPRLE RILLAKERIR FVIKKHELLN STREDLQIDK PASGVKEEWY ARITKLRKMV DQLFCKKFAE ALGSTEAKAV PYQKFEAHPN DLYVEGLPEN IPFRSPSWYG IRRLEKIIQV GNRIKFVIKR PELLTHSTTE VTQPRTNTPV KEDWNVRITK LRKOVEEIFN LKFAOALGLT EAVKVPYPVF ESNPEFLYVE GLPEGIPFRS PTWEGIPRLE RIVRGSNKIK FVVKKPELVV SYLPPGMASK INTKALQSPK RPRSPGSNSK VPEIEVTVEG PNNSSPQTSA VRTPTQTNGS NVPFKPRGRE FSFEAWNAKI TDLKQKVENL FNEKCGEALG LKOAVKVPFA LFESFPEDFY VEGLPEGVPF RRPSTFGIPR LEKILRNKAK IKFIIKKPEM FETAIKESTS SKSPPRKINS SPNVNTTASG VEDLNIIQVT IPDDDNERLS KVEKARQLRE QVNDLFSRKF GEAIGMGFPV KVPYRKITIN PGCVVVDGMP PGVSFKAPSY IEISSMRRIL DSAEFIKFTV IRPFPGLVIN NQLVDQNESE GPVIQESAEA SQLEVPVTEE IKETDGSSQI KQEPDPTW

FIGURE 4 | (A) Proteins extracted from NFS-25 cells cultured with DS-biotin (DSb) or without (CT, control) and analyzed by SDS-PAGE. The two arrows indicated two forms of GTF21. (B) The identity of GTF2I is confirmed by blotting with anti-GTF21. (C) Amino acid sequence of GTF2l (canonical isoform 1) with green regions highlighting peptides that were identified by mass spectrometric sequencing of the gel band indicated by the upper arrow in (A).

sequence BLAST, the peptides identified by mass spectrometry (covering 462 amino acid residues) did not align perfectly with any single known GTF2I isoform. But they did align best with mouse isoform X21 and aligned well with 30 other mouse isoforms.

\section{DS Affinity Protein Network and IgH-Associated ER Complex}

We reasoned that a potential DS receptor in a cellular molecular complex first needs to be accessible to allow DS association. Therefore, we attempted to tag accessible proteins in NFS-25 
cells with amine-reactive biotin (sulfo-NHS-SS-biotin). Total proteins extracted from tagged cells were loaded onto DSaffinity resins and washed with $0.6 \mathrm{M} \mathrm{NaCl}$, and those remaining tightly bound to DS were eluted with $1.0 \mathrm{M} \mathrm{NaCl}$ and collected. Biotin-tagged proteins were then pulled down with NeutrAvidin beads, separated in SDS-PAGE gels, and blotted with streptavidin-HRP for confirmation. Three unique bands were identified compared to those from mock experiments.

Mass spectrometry sequencing of these bands identified 40 proteins with a minimum of 6 peptide matches as a cut-off (Supplemental Table 1). These proteins are predominantly associated with the ER or the nucleus. Among these 40 proteins, 17 can be located to the ER, including BiP/GRp78 (Hspa5), Hsp90b1, Hsp90ab1, Ganab, VCP, Hspd1, Canx, Kpnb1, Hspa8, Pdia3, P4hb, Pdia4, Prkcsh, Rpn2, Hspa9, Cct8, and Cct3. 28 can be located to the nucleus, of which 8 both to the nucleus and the ER. The 20 exclusively nuclear proteins are Ncl, Hsp90aal, Xrcc6, Xrcc5, Prmt5, Lmnb1, Eftud2, Supt16h, Supt5h, Mfap1b, Pkm, Hnrnpu, Ssrp1, Nasp, Mcm6, Actn4, Nap1l1, Eif3l, Pabpc1, and Tfrc. The remaining 3 proteins may be located to the cytoplasm or the cell membrane (Eif3b, Snx2, and Lck).

STRING protein-protein network analysis revealed that these 40 proteins have significantly more interactions than expected (Figure 5). This network has 40 nodes and 182 edges (interactions) with average node degree of 9.1, average local clustering coefficient of 0.609 , and PPI (protein-protein interaction) enrichment $\mathrm{p}$-value of $<1.0 \mathrm{E}-16$, whereas a random set of 40 proteins is expected to have 42 edges. Based on KEGG pathway analysis, Protein Processing in the ER is the most significant for these proteins, with 13/161 counts in the network, 1.65 strength, and 1.80E-16 false discovery rate. Based on Gene Ontology analysis, Protein Folding is the most significant biological process from these proteins, with $12 / 153$ counts in the network, 1.64 strength, and 1.53E-13 false discovery rate.

Pathway and process enrichment analysis by Metascape also revealed that these proteins are most significantly associated with Protein Folding (with $\log _{10}(\mathrm{P})$ value of -20.6) and Protein Processing in the ER (with $\log _{10}(\mathrm{P})$ value of -18.1). The Molecular Complex Detection (MCODE) algorithm applied to the densely connected network identified a single dominant complex among these DS-affine proteins, the $\operatorname{IgH}$ chain associated ER-localized multiprotein complex.

\section{DISCUSSION}

In this paper, we provide several lines of evidence to support DS as a regulator of autoreactive $\mathrm{B}$ cell development at the pre-B stage via interaction with the IgH $\mu$ chain of the pre-BCR. Using CD5+ pre-B lymphoblast NSF-25 cells as a model, we show that DS interacts with IgH on the pre-B cell surface in distinct clusters, associates with an IgH-associated multiprotein complex in the ER, and binds the general transcription factor GTF2I that may facilitate gene expression of $\mathrm{IgH}$ and other genes in the nucleus.

Based on these findings and our previous studies (1-9), we propose an (DS•autoAg)-autoBCR dual-signal model for

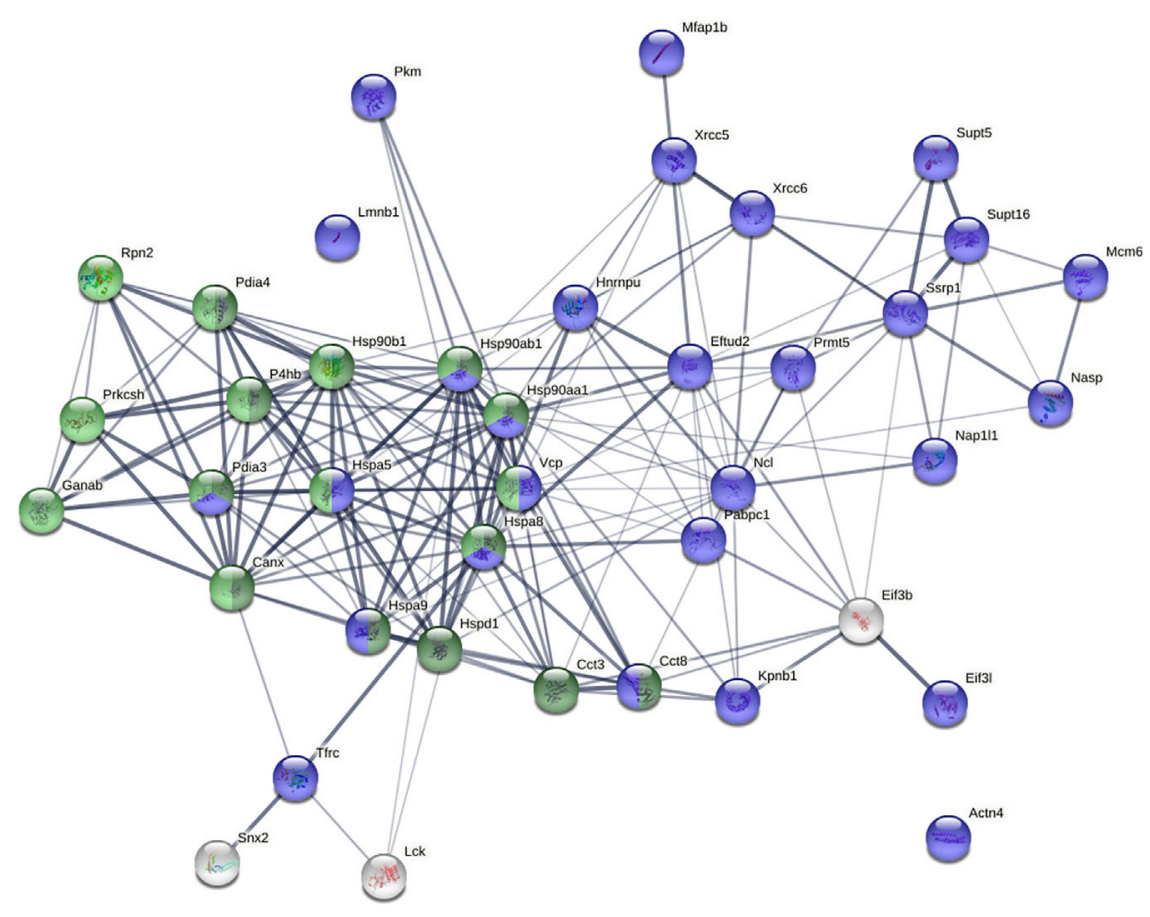

FIGURE 5 | Protein-protein interaction network of the 40 biotin-tagged DS-binding proteins. Green: proteins involved in protein processing in the ER. Dark green: proteins involved in protein folding in the ER. Blue: nuclear proteins. 
initiating autoreactive B1 cell activation (Figure 6): (i) DS and autoAgs from dying cells form non-covalent autoAg•DS complexes; (ii) upon encountering autoreactive B cells, an autoAg engages an autoBCR and binds to part of the variable domain (e.g., CDR1 and CDR2); (iii) because of its complexation with the autoAg, DS is brought into close contact with the autoBCR and binds to the IgH portion of the autoBCR (e.g., CDR3); (iv) (DS•autoAg)-autoBCR complexes internalize, and $\mathrm{DS} / \mathrm{IgH}$ complexes accumulate in the ER where they may recruit $\mathrm{IgH}$-associated protein processing complexes to facilitate folding and assembly of newly synthesized Ig; (v) somewhere along the way, DS binds GTF2I and transports it to nucleus, and in the nucleus, GTF2I upregulates transcription of the $I g H$ locus and other gene targets. In summary, the intricate interactions of DS with Ig-associated complex in the ER and GTF2I may provide a positive feedback loop to upregulate $\operatorname{IgH}$ at gene and protein levels.

The IgH repertoire is generally thought to be positively selected at the pre-BCR checkpoint (12). The pre-BCR assesses the quality of IgH chains and tunes the repertoire by driving the preferential expansion and differentiation of cells with higher quality of $\operatorname{IgH} \mu$ chains (20). Approximately $9 \%$ of in-frame IgH $\mu$ transcripts in human pro-B cells encode unusual IgH that can be expressed on the cell surface in the absence of surrogate or conventional light chains, and these IgH chains demonstrate preferential use of certain $\mathrm{VH}$ genes and an increased number of positively charged amino acid residues within the CDR3 region (14). Given that DS displays a high density repeating negative charges (on average, one carboxylate and one sulfate per repeating unit), we speculate that DS binds $\operatorname{IgH}$ at the CDR3 region.

Stromal cell-associated heparan sulfate, which is structurally similar to DS, has been proposed to be a potential pre-BCR ligand, as binding between pre-BCR and stromal cells could be specifically blocked by heparin, heparinase, or a sulfate inhibitor (21). Moreover, the binding required the unique $\lambda 5$ tail, which protrudes from the pre-BCR molecule at the same position where the CDR3 of a conventional light chain is located (21). We had tested heparan sulfate, heparin, and other glycosaminoglycans in our previous studies, but found DS to be the most potent glycosaminoglycan for stimulating B1 cells (1, 3 ) and hence have focused on DS. Among the three components of the pre-BCR, our study found that IgH $\mu$ possesses strong DS affinity and $\lambda 5$ weaker affinity (Figure 3 ). It is possible that DS binds to a positively charged IgH CDR3 conformation that is enforced by the $\lambda 5$ tail or conventional light chain CDR3.

Although synthesis and assembly rate of pre-BCR and BCR components are comparable, the pre-BCR is controlled by a highly efficient ER retention mechanism, which only allows exit of a few percent of the complexes from the ER (22). Furthermore,

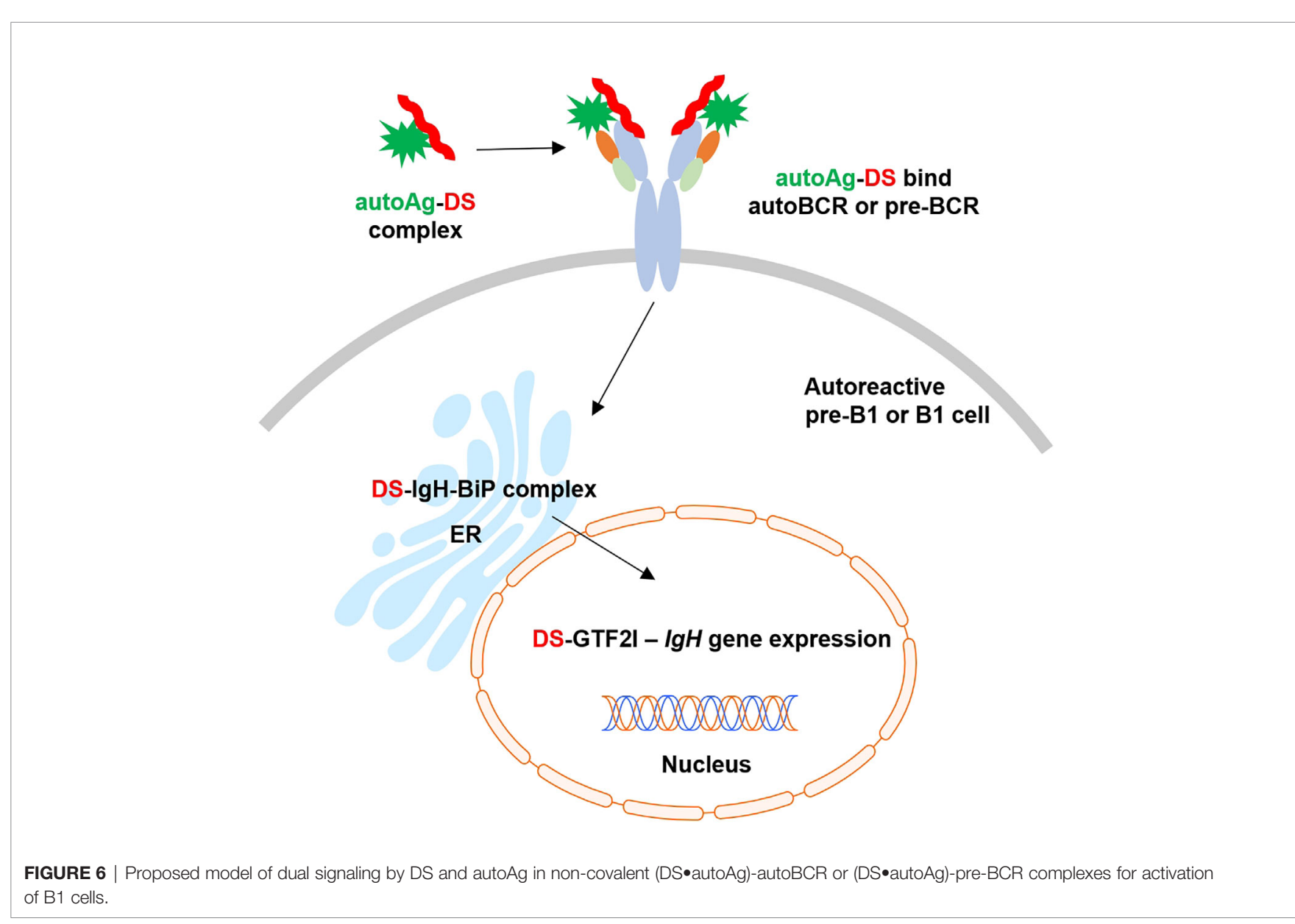


this retention mechanism is restricted to $\operatorname{IgH}$ and not selective for the surrogate light chain, thus appearing to be inherent to pre-B cells. Pre-B lymphocytes and hybridomas derived from them synthesize $\mathrm{IgH}$ in the absence of light chains, and $\mathrm{BiP}$ binds the $\mathrm{CH} 1$ domain of the free $\mathrm{IgH}$ and thus retains it in the ER $(23,24)$. BiP also binds light chains shortly after their translation, and newly synthesized heavy and light chains interact sequentially with $\operatorname{BiP}$ and Grp94 in the $\operatorname{ER}(25,26)$. BiP and other ER molecules strictly control the processing and assembly of immunoglobulins, and our current study identify DS as another critical player of the Ig-associated ER complex.

B cells synthesize large amounts of immunoglobulins, which makes these cells particularly sensitive to ER stress. When $\mathrm{CHO}$ cells were transfected with an IgH $\mu$ chain, expressed $\mu$ chain accumulated in the cells and formed stable complexes with BiP, and the synthesis of three ER stress proteins (BiP, Grp94, and ERp72) increased at both protein and mRNA levels (27). We have shown that DS accumulates in the ER and has affinity to these and other stress proteins. It is possible that DS interaction with ER stress proteins plays a decisive role in steering B1 cell fate, as DS appears to interact with ER proteins in both viable and dying cells (Supplemental Figure 6).

Our study shows, for the first time, GTF2I protein as a direct DS-interacting partner in pre-B cells. The GTF2I gene is well known for its association with Williams-Beuren syndrome and supravalvular aortic stenosis (28). Amazingly, recent large-scale genome-wide association studies have identified close association of the GTF2I gene with various autoimmune diseases, including primary Sjögren syndrome (29), systemic lupus erythematosus (30), rheumatoid arthritis (31), myasthenia gravis (32), ANCAassociated vasculitis (33), and neuromyelitis optica spectrum disorder (34).

GTF2I proteins are unusual transcriptional regulators that function as both basal and signal-induced transcription factors. Among its related pathways are the BCR signaling pathway and RNA polymerase II transcription initiation and promoter clearance. GTF2I protein interacts with Btk (Bruton's tyrosine kinase), ARID3A (AT-rich interaction domain), HDAC3 (histone deacetylase 3), and others (19). GTF2I controls B cell proliferation by regulating both nuclear translocation of $\mathrm{c}$-Rel and DNA-binding activity of NF-kappaB (35).

GTF2I interacts directly with B cell-specific coactivator OCA$\mathrm{B}$ and regulates IgH gene transcription by facilitating enhancerpromoter communication (36). GTF2I is also required for induction of $\mathrm{IgH}$ gene transcription through transcription factor Bright (B cell regulator of immunoglobulin heavy chain transcription) (37). GTF2I, Btk, and Bright function as a threecomponent protein complex at the IgH gene locus. GTF2I and Btk exist in a complex before BCR engagement, and in response to BCR crosslinking, GTF2I becomes transiently phosphorylated on Tyr248, Tyr357, and Tyr462 $(38,39)$. Multiple kinases can independently target GTF2I via distinct signaling pathways. In addition to Btk (40), GTF2I undergoes c-Src-dependent phosphorylation on Tyr248 and Tyr611 and translocates from the cytoplasm to the nucleus (41).

GTF2I is required for optimal induction of GRP78/BiP and others in the ER stress response $(42,43)$. When cells experience ER stress, the transcription of a family of glucose-regulated protein $(G R P)$ genes which encode various ER chaperones is induced. The $G R P$ promoters contain multiple copies of ER stress response element (ERSE), consisting of a unique CCAAT $\left(\mathrm{N}_{9}\right)$ CCACG tripartite structure with $\mathrm{N}_{9}$ being a GC-rich sequence of 9 bp that is conserved across species (43). GTF2I isoforms bind directly to the ERSEs of grp78 and ERp72 (PDIA4) promoters, and the stimulation of ERSE-mediated transcription by GTF2I requires consensus tyrosine phosphorylation sites on GTF2I and the ERSE GGC sequence motif (43). GTF2I binds the Grp78 gene promoter and in turn regulates Grp78 transcription and synthesis (44). In our study, we identified GRP78 (BiP), GRP94 (Hsp90b1) and ERp72 (PDIA4), as well as a number of other ER stress chaperones such as GRP75 (Hspa9), Hsp90ab1, Hspd1, Hspa8, and Hsp90aal as DSbinding proteins (Figure 5 and Supplemental Table 1). It is possible that GTF2I regulates the transcription of these proteins.

Our study also identified 20 nuclear proteins, which are likely involved in GTF2I associated gene transcription activities. In addition, LCK is identified as a DS-associated protein. Although typically regarded as a T-cell specific tyrosine kinase, LCK is an important mediator of BCR signaling in B-cell chronic lymphocyte leukemia (B-CLL) and found at significant levels in CD5+ B1 cells $(45,46)$. In mice, LCK is also expressed by CD5+ B1 cells and involved in modulating BCR signal transduction in B1 cells $(47,48)$.

In our previous studies, we have demonstrated that DS has strong affinity to over 200 autoAgs and proposed that autoAgs and DS form macromolecular complexes and cooperate to stimulate autoreactive B cells $(1,2,4,5)$. Therefore, we have been searching for DS receptors in autoreactive B cells. In this study, we identified $\operatorname{IgH} \mu$ of the pre-BCR as a novel DS receptor. Pre-BCRs resemble polyreactive autoBCRs in their capability of recognizing multiple autoAgs (11). Autoreactive B1 cells differ from conventional B-2 cells in their responses to BCR signaling. While binding of foreign antigens to BCRs on B-2 cells leads to cell activation, repeated encounters with autoAgs switch B1 cells either into an anergic state or lead to apoptosis.

We propose a model of (DS•autoAg)-preBCR or (DS•autoAg)autoBCR dual signaling that activates autoreactive $B$ cells (Figure 6). In this model, both autoAg and DS cooperate and bind simultaneously to different parts of the autoBCR. Once internalized with the BCR complex, DS recruits a network of additional partners that aids initial B1 cell activation to proceed to the next stages of B cell development.

However, it should be noted that the development of autoreactive B1 cells is far from clear. The requirement for a preBCR checkpoint has remained debatable, while a lineage model favors a distinct $\mathrm{B} 1$ progenitor cell for B1 cells, a selection model argues that a common $\mathrm{B}$-cell progenitor gives rise to both $\mathrm{B} 1$ and $\mathrm{B} 2$ cells (49). The roles of DS or other glycosaminoglycans in B lymphocyte development are also far from clear. For example, DS-deficient mice have been found to have neonatally lethal embryological defects, but the development of secondary lymphoid organs, such as the lymph node and spleen, appeared to be normal (50). Given the complexity of B-cell development and the numerous interacting partners of DS in different tissues, further studies will be needed for a better understanding of autoreactive B1 cells. 
In summary, this study provides several lines of evidence that support DS as a potential regulator of $\mathrm{IgH}$ in pre-B cells. DS interacts directly with IgH on the cell surface, with IgHassociated protein processing complexes in the ER, and with the GTF2I transcription factor that is required for $I g H$ transcription. Through its affinity with autoAgs and its control of $\mathrm{IgH}$, DS emerges as a potential key player in the development of autoreactive B cells and autoimmunity.

\section{DATA AVAILABILITY STATEMENT}

The original contributions presented in the study are included in the article/Supplementary Material. Further inquiries can be directed to the corresponding authors.

\section{AUTHOR CONTRIBUTIONS}

JL carried out the experiments. JR assisted with experiments. MR consulted on the study and edited the manuscript. JW directed the study, analyzed the data, and wrote the manuscript. All authors contributed to the article and approved the submitted version.

\section{REFERENCES}

1. Wang JY, Lee J, Yan M, Rho JH, Roehrl MH. Dermatan Sulfate Interacts With Dead Cells and Regulates CD5(+) B-Cell Fate: Implications for a Key Role in Autoimmunity. Am J Pathol (2011) 178(5):2168-76. doi: 10.1016/ j.ajpath.2011.01.028

2. Rho JH, Zhang W, Murali M, Roehrl MH, Wang JY. Human Proteins With Affinity for Dermatan Sulfate Have the Propensity to Become Autoantigens. Am J Pathol (2011) 178(5):2177-90. doi: 10.1016/j.ajpath.2011.01.031

3. Wang JY, Roehrl MH. Glycosaminoglycans are a Potential Cause of Rheumatoid Arthritis. Proc Natl Acad Sci USA (2002) 99(22):14362-7. doi: $10.1073 /$ pnas.222536599

4. Zhang W, Rho JH, Roehrl MH, Wang JY. A Comprehensive AutoantigenOme of Autoimmune Liver Diseases Identified From Dermatan Sulfate Affinity Enrichment of Liver Tissue Proteins. BMC Immunol (2019) 20 (1):21. doi: 10.1186/s12865-019-0304-1

5. Zhang W, Rho JH, Roehrl MW, Roehrl MH, Wang JY. A Repertoire of 124 Potential Autoantigens for Autoimmune Kidney Diseases Identified by Dermatan Sulfate Affinity Enrichment of Kidney Tissue Proteins. PloS One (2019) 14(6):e0219018. doi: 10.1371/journal.pone.0219018

6. Wang JY, Zhang W, Rho JH, Roehrl MW, Roehrl MH. A Proteomic Repertoire of Autoantigens Identified From the Classic Autoantibody Clinical Test Substrate HEp-2 Cells. Clin Proteomics (2020) 17:35. doi: 10.1186/s12014-020-09298-3

7. Wang JY, Zhang W, Roehrl MW, Roehrl VB, Roehrl MH. An Autoantigen Profile of Human A549 Lung Cells Reveals Viral and Host Etiologic Molecular Attributes of Autoimmunity in COVID-19. J Autoimmun (2021) 120:102644. doi: 10.1101/2021.02.21.432171

8. Wang JY, Zhang W, Roehrl MW, Roehrl VB, Roehrl MH. An Autoantigen Atlas From Human Lung HFL1 Cells Offers Clues to Neurological and Diverse Autoimmune Manifestations of COVID-19. bioRxiv (2021). doi: 10.1101/2021.01.24.427965

9. Wang JY, Zhang W, Roehrl VB, Roehrl MW, Roehrl MH. An Autoantigenome From HS-Sultan B-Lymphoblasts Offers a Molecular Map for Investigating Autoimmune Sequelae of COVID-19. bioRxiv (2021) 2021:4.05.438500. doi: 10.1101/2021.04.05.438500

10. Davidson WF, Fredrickson TN, Rudikoff EK, Coffman RL, Hartley JW, Morse HC. A Unique Series of Lymphomas Related to the Ly-1+ Lineage of B Lymphocyte Differentiation. J Immunol (1984) 133(2):744-53.

\section{FUNDING}

This work was partially supported by Curandis and the NIH of the United States. The funder was not involved in the study design, collection, analysis, interpretation of data, the writing of this article or the decision to submit it for publication. MR acknowledges NCI R21 CA251992, funding from a Cycle for Survival Equinox innovation grant, and the MSKCC NIH/NCI Cancer Center Support Grant P30 CA008748.

\section{ACKNOWLEDGMENTS}

We thank Ross Tomaino and the Taplin Biological Mass Spectrometry facility of Harvard Medical School for expert service with protein sequencing.

\section{SUPPLEMENTARY MATERIAL}

The Supplementary Material for this article can be found online at: https://www.frontiersin.org/articles/10.3389/fimmu.2021.680212/ full\#supplementary-material

11. Kohler F, Hug E, Eschbach C, Meixlsperger S, Hobeika E, Kofer J, et al. Autoreactive B Cell Receptors Mimic Autonomous Pre-B Cell Receptor Signaling and Induce Proliferation of Early B Cells. Immunity (2008) 29 (6):912-21. doi: 10.1016/j.immuni.2008.10.013

12. Winkler TH, Mårtensson IL. The Role of the Pre-B Cell Receptor in B Cell Development, Repertoire Selection, and Tolerance. Front Immunol (2018) 9:2423. doi: 10.3389/fimmu.2018.02423

13. Bankovich AJ, Raunser S, Juo ZS, Walz T, Davis MM, Garcia KC. Structural Insight Into Pre-B Cell Receptor Function. Science (2007) 316(5822):291-4 doi: $10.1126 /$ science.1139412

14. Minegishi Y, Conley ME. Negative Selection At the pre-BCR Checkpoint Elicited by Human Mu Heavy Chains With Unusual CDR3 Regions. Immunity (2001) 14(5):631-41. doi: 10.1016/s1074-7613(01) 00131-5

15. Grimsholm O, Ren W, Bernardi AI, Chen H, Park G, Camponeschi A, et al. Absence of Surrogate Light Chain Results in Spontaneous Autoreactive Germinal Centres Expanding V(H)81X-Expressing B Cells. Nat Commun (2015) 6:7077. doi: 10.1038/ncomms8077

16. Aoyama E, Yoshihara R, Tai A, Yamamoto I, Gohda E. PKC- and PI3Kdependent But ERK-independent Proliferation of Murine Splenic B Cells Stimulated by Chondroitin Sulfate B. Immunol Lett (2005) 99(1):80-4. doi: 10.1016/j.imlet.2005.01.005

17. Yoshihara R, Aoyama E, Kadota Y, Kawai S, Goto T, Zhong M, et al. Differentiation of Murine B Cells Induced by Chondroitin Sulfate B. Cell Immunol (2007) 250(1-2):14-23. doi: 10.1016/j.cellimm.2007.12.002

18. Karasuyama H, Rolink A, Melchers F. A Complex of Glycoproteins is Associated With VpreB/lambda 5 Surrogate Light Chain on the Surface of Mu Heavy Chain-Negative Early Precursor B Cell Lines. J Exp Med (1993) 178 (2):469-78. doi: 10.1084/jem.178.2.469

19. Roy AL. Pathophysiology of TFII-I: Old Guard Wearing New Hats. Trends Mol Med (2017) 23(6):501-11. doi: 10.1016/j.molmed.2017.04.002

20. Kawano Y, Yoshikawa S, Minegishi Y, Karasuyama H. Pre-B Cell Receptor Assesses the Quality of IgH Chains and Tunes the Pre-B Cell Repertoire by Delivering Differential Signals. J Immunol (2006) 177(4):2242-9. doi: 10.4049/ jimmunol.177.4.2242

21. Bradl H, Wittmann J, Milius D, Vettermann C, Jäck HM. Interaction of Murine Precursor B Cell Receptor With Stroma Cells is Controlled by the Unique Tail of Lambda 5 and Stroma Cell-Associated Heparan Sulfate. J Immunol (2003) 171(5):2338-48. doi: 10.4049/jimmunol.171.5.2338 
22. Brouns GS, de Vries E, Neefjes JJ, Borst J. Assembled Pre-B Cell Receptor Complexes are Retained in the Endoplasmic Reticulum by a Mechanism That is Not Selective for the Pseudo-Light Chain. J Biol Chem (1996) 271 (32):19272-8. doi: 10.1074/jbc.271.32.19272

23. Haas IG, Wabl M. Immunoglobulin Heavy Chain Binding Protein. Nature (1983) 306(5941):387-9. doi: 10.1038/306387a0

24. Lee YK, Brewer JW, Hellman R, Hendershot LM. Bip and Immunoglobulin Light Chain Cooperate to Control the Folding of Heavy Chain and Ensure the Fidelity of Immunoglobulin Assembly. Mol Biol Cell (1999) 10(7):2209-19. doi: $10.1091 / \mathrm{mbc} \cdot 10.7 .2209$

25. Knittler MR, Haas IG. Interaction of BiP With Newly Synthesized Immunoglobulin Light Chain Molecules: Cycles of Sequential Binding and Release. EMBO J (1992) 11(4):1573-81. doi: 10.1002/j.1460-2075.1992.tb05202.x

26. Melnick J, Dul JL, Argon Y. Sequential Interaction of the Chaperones BiP and GRP94 With Immunoglobulin Chains in the Endoplasmic Reticulum. Nature (1994) 370(6488):373-5. doi: 10.1038/370373a0

27. Lenny N, Green M. Regulation of Endoplasmic Reticulum Stress Proteins in COS Cells Transfected With Immunoglobulin Mu Heavy Chain Cdna. J Biol Chem (1991) 266(30):20532-7. doi: 10.1016/S0021-9258(18)54957-7

28. Palmer SJ, Santucci N, Widagdo J, Bontempo SJ, Taylor KM, Tay ES, et al. Negative Autoregulation of GTF2IRD1 in Williams-Beuren Syndrome Via a Novel DNA Binding Mechanism. J Biol Chem (2010) 285(7):4715-24. doi: $10.1074 /$ jbc.M109.086660

29. Li Y, Zhang K, Chen H, Sun F, Xu J, Wu Z, et al. A Genome-Wide Association Study in Han Chinese Identifies a Susceptibility Locus for Primary Sjögren's Syndrome At 7q11.23. Nat Genet (2013) 45(11):1361-5. doi: 10.1038/ng.2779

30. Sun C, Molineros JE, Looger LL, Zhou XJ, Kim K, Okada Y, et al. HighDensity Genotyping of Immune-Related Loci Identifies New SLE Risk Variants in Individuals With Asian Ancestry. Nat Genet (2016) 48(3):32330. doi: 10.1038/ng.3496

31. Kim K, Bang SY, Ikari K, Yoo DH, Cho SK, Choi CB, et al. AssociationHeterogeneity Mapping Identifies an Asian-specific Association of the GTF2I Locus With Rheumatoid Arthritis. Sci Rep (2016) 6:27563. doi: 10.1038/srep27563

32. Ruan X, Lu X, Gao J, Jiang L, Zhu Y, Zhou Y, et al. Multiomics Data Reveals the Influences of Myasthenia Gravis on Thymoma and its Precision Treatment. J Cell Physiol (2021) 236(2):1214-27. doi: 10.1002/jcp.29928

33. Yokoyama N, Kawasaki A, Matsushita T, Furukawa H, Kondo Y, Hirano F, et al. Association of NCF1 Polymorphism With Systemic Lupus Erythematosus and Systemic Sclerosis But Not With ANCA-associated Vasculitis in a Japanese Population. Sci Rep (2019) 9(1):16366. doi: 10.1038/s41598-019-52920-0

34. Liang H, Gao W, Liu X, Liu J, Mao X, Yang M, et al. The GTF2I rs117026326 Polymorphism is Associated With Neuromyelitis Optica Spectrum Disorder But Not With Multiple Sclerosis in a Northern Han Chinese Population. J Neuroimmunol (2019) 337:577045. doi: 10.1016/j.jneuroim.2019.577045

35. Ashworth T, Roy AL. Cutting Edge: TFII-I Controls B Cell Proliferation Via Regulating NF-Kappab. J Immunol (2007) 178(5):2631-5. doi: 10.4049/ jimmunol.178.5.2631

36. Ren X, Siegel R, Kim U, Roeder RG. Direct Interactions of OCA-B and TFII-I Regulate Immunoglobulin Heavy-Chain Gene Transcription by Facilitating Enhancer-Promoter Communication. Mol Cell (2011) 42(3):342-55. doi: 10.1016/j.molcel.2011.04.011

37. Rajaiya J, Nixon JC, Ayers N, Desgranges ZP, Roy AL, Webb CF. Induction of Immunoglobulin Heavy-Chain Transcription Through the Transcription Factor Bright Requires TFII-I. Mol Cell Biol (2006) 26(12):4758-68. doi: 10.1128/MCB.02009-05

38. Yang W, Desiderio S. Bap-135, a Target for Bruton's Tyrosine Kinase in Response to B Cell Receptor Engagement. Proc Natl Acad Sci USA (1997) 94 (2):604-9. doi: 10.1073/pnas.94.2.604
39. Egloff AM, Desiderio S. Identification of Phosphorylation Sites for Bruton's Tyrosine Kinase Within the Transcriptional Regulator BAP/TFII-I. J Biol Chem (2001) 276(30):27806-15. doi: 10.1074/jbc.M103692200

40. Sacristán C, Tussié-Luna MI, Logan SM, Roy AL. Mechanism of Bruton's Tyrosine Kinase-Mediated Recruitment and Regulation of TFII-I. J Biol Chem (2004) 279(8):7147-58. doi: 10.1074/jbc.M303724200

41. Cheriyath V, Desgranges ZP, Roy AL. c-Src-dependent Transcriptional Activation of TFII-I. J Biol Chem (2002) 277(25):22798-805. doi: 10.1074/ jbc.M202956200

42. Racek T, Buhlmann S, Rüst F, Knoll S, Alla V, Pützer BM. Transcriptional Repression of the Prosurvival Endoplasmic Reticulum Chaperone GRP78/BIP by E2F1. J Biol Chem (2008) 283(49):34305-14. doi: 10.1074/jbc.M803925200

43. Parker R, Phan T, Baumeister P, Roy B, Cheriyath V, Roy AL, et al. Identification of TFII-I as the Endoplasmic Reticulum Stress Response Element Binding Factor ERSF: its Autoregulation by Stress and Interaction With ATF6. Mol Cell Biol (2001) 21(9):3220-33. doi: 10.1128/mcb.21.9.32203233.2001

44. Misra UK, Wang F, Pizzo SV. Transcription Factor TFII-I Causes Transcriptional Upregulation of GRP78 Synthesis in Prostate Cancer Cells. J Cell Biochem (2009) 106(3):381-9. doi: 10.1002/jcb.22016

45. Talab F, Allen JC, Thompson V, Lin K, Slupsky JR. LCK is an Important Mediator of B-cell Receptor Signaling in Chronic Lymphocytic Leukemia Cells. Mol Cancer Res (2013) 11(5):541-54. doi: 10.1158/1541-7786.MCR-120415-T

46. Majolini MB, D’Elios MM, Galieni P, Boncristiano M, Lauria F, Del Prete G, et al. Expression of the T-cell-specific Tyrosine Kinase Lck in Normal B-1 Cells and in Chronic Lymphocytic Leukemia B Cells. Blood (1998) 91 (9):3390-6. doi: 10.1182/blood.V91.9.3390.3390_3390_3396

47. Dal Porto JM, Burke K, Cambier JC. Regulation of BCR Signal Transduction in B-1 Cells Requires the Expression of the Src Family Kinase Lck. Immunity (2004) 21(3):443-53. doi: 10.1016/j.immuni.2004.07.018

48. Ulivieri C, Valensin S, Majolini MB, Matthews RJ, Baldari CT. Normal B-1 Cell Development But Defective BCR Signaling in Lck-/- Mice. Eur J Immunol (2003) 33(2):441-5. doi: 10.1002/immu.200310019

49. Wong JB, Hewitt SL, Heltemes-Harris LM, Mandal M, Johnson K, Rajewsky K, et al. B-1a Cells Acquire Their Unique Characteristics by Bypassing the preBCR Selection Stage. Nat Commun (2019) 10(1):4768. doi: 10.1038/s41467019-12824-z

50. Stachtea XN, Tykesson E, van Kuppevelt TH, Feinstein R, Malmström A, Reijmers RM, et al. Dermatan Sulfate-Free Mice Display Embryological Defects and Are Neonatal Lethal Despite Normal Lymphoid and NonLymphoid Organogenesis. PloS One (2015) 10(10):e0140279. doi: 10.1371/ journal.pone.0140279

Conflict of Interest: JR is employed by MP Biomedicals New Zealand Ltd. MR is on the scientific advisory boards of Trans-Hit, Proscia, and Universal DX. JW is the founder of Curandis. None of these companies had influence on the design, interpretation, or decision to publish of this study.

The remaining authors declare that the research was conducted in the absence of any commercial or financial relationships that could be construed as a potential conflict of interest.

Copyright (C) 2021 Lee, Rho, Roehrl and Wang. This is an open-access article distributed under the terms of the Creative Commons Attribution License (CC BY). The use, distribution or reproduction in other forums is permitted, provided the original author(s) and the copyright owner(s) are credited and that the original publication in this journal is cited, in accordance with accepted academic practice. No use, distribution or reproduction is permitted which does not comply with these terms. 